\title{
OS PRINCÍPIOS DO EFEITO DIRETO E DA APLICABILIDADE DIRETA NO DIREITO DA UNIÃO EUROPEIA
}

\section{THE PRINCIPLES OF DIRECT EFFECT AND APPLICABILITY DIRECT IN RIGHT OF THE EUROPEAN UNION}

\author{
${ }^{1}$ Ana Luisa de Oliveira Ribeiro
}

\section{RESUMO}

O presente artigo versa sobre os princípios da aplicabilidade direta e do efeito direto das normas do Direito da União Europeia. Para tanto, realizar-se-á uma breve abordagem histórica da gênese da União Europeia, bem como de seus tratados constitutivos, a fim de se aludir, posteriormente, à analise principiológica. Ademais, cuidará das peculiaridades teóricas e práticas atrelada aos aludidos princípios e suas incidências no âmbito do Tribunal de Justiça da União Europeia. Por fim, visa analisar o modo como a interpretação jurídica do Direito da União atua concomitantemente às soberanias dos Estados signatários deste processo integracional.

Palavras-chave: Direito da união, Princípio do efeito direto, Princípio da aplicabilidade direta, Interpretação conforme o direito da união

\begin{abstract}
ABSTRACT: This article discusses about the principles of direct applicability and direct effect applied the rules of Law European Union. To do so, will be held a brief historical associated with the genesis of the European Union and its constituent treaties, in order to allude later to analysis of referred principles. Moreover, take care of their theoretical and practices peculiarities, verify their impact within the Court of Justice of the European Union and, lastly, analyze how the legal interpretation under the law of Europe Union work with the sovereignty of the States members of this integration process.
\end{abstract}

Keywords: Europe union law, Principle of direct applicability, Principle of direct effect, Interpretation under the law of europe union

\footnotetext{
${ }^{1}$ Mestra em Direito pela Pontifícia Universidade Católica de Minas Gerais, PUC/Minas, Minas gerais, MG. (Brasil) e Advogada. E-mail: analuisaribeiro.adv@gmail.com
} 


\section{INTRODUÇÃO}

O Direito da União Europeia destaca-se, no estudo jurídico mundial, por compreender em seu arcabouço normativo e principiológico disposições e preceitos até então inexistentes em qualquer modelo de Estado ou bloco econômico. Destaca-se, assim, não somente por consubstanciar-se em um modelo inovador de processo integracional dos Estados europeus, mas também por sua efetividade. Trata-se de uma integração que emergiu diante do acordo entre os países europeus em conferirem parte de sua soberania a uma unidade integracional, a fim de se maximizar a aliança entre os povos, fortalecer as políticas e economias nacionais e, igualmente, coibir possíveis desavenças militares.

Para tanto, a Comunidade Europeia de Carvão e Aço, inicialmente concebida pelo Tratado de Paris de 1951, sofreu alterações e evoluções para se chegar no que hoje se configura como União Europeia. Após o advento do Tratado de Roma, em 1957, constituiu-se a Comunidade Econômica Europeia, vislumbrando o mercado comum Europeu e, por fim, com o Tratado de Maastricht, em 1992 concebe-se a União Europeia, dotada de autonomia e de um arcabouço normativo próprio, no âmbito jurídico. Posteriormente, o Tratado de Lisboa, de 1997 estabelece novas diretrizes ao processo integracional inovando com um texto que se assemelha, em muitos aspectos, ao texto Constitucional de um Estado, embora não possa ser concebida na acepção plena do termo Constituição (BORCHARDT, 2011).

Para a efetividade do Direito da União entre os países signatários, implementou-se princípios singulares e aparatos sem os quais provavelmente a União Europeia estaria descaracterizada. Princípios como da autonomia da ordem jurídico comunitária, da subsidiariedade, da lealdade comunitária e da responsabilidade patrimonial dos Estados membros quando da violação de preceitos do Direito da União, e por fim, os princípios do efeito direto e da aplicabilidade direta, objetos do presente trabalho.

A incidência do princípio do efeito direto se verifica na esfera da prevalência da norma do Direito da União em face do direito nacional, bem como na uniformidade na sua aplicação no caso concreto e, consequentemente, em uma interpretação conforme a este Direito (GORJÃO, 2010). Nessa perspectiva, os países europeus tem o dever de estabelecer mecanismos para a plena aplicação dos preceitos comunitários, seja no âmbito do efeito direto horizontal- onde os particulares invocam as normas comunitárias em face aos mesmos- ou no caso do efeito direto vertical- com relação ao particular e o Estado, quando da violação de preceitos comunitários (GORJÃO, 2010). 
Por conseguinte, o princípio da aplicabilidade direta consiste em um desdobramento do princípio do efeito direto, conforme o qual os países signatários da União Europeia devem incorporar os preceitos normativos do Direito da União Europeia em seu direito pátrio a fim de obter o efeito direto de tais disposições, mesmo diante a não observância de procedimento legislativo de recepção de normas concernentes a tratados internacionais (LEAL et al., 2001).

Pretende-se, assim, demonstrar como o Princípio do efeito direto e o decorrente princípio da aplicabilidade direta consubstanciam-se como inovações no âmbito judicial e legislativo do ordenamento jurídico mundial, ao passo que permite com que cidadãos instaurem demandas judiciais nas jurisdições de seus países de origem recorrendo à fundamentação de uma violação de uma norma comunitária, sem a mesma ser incorporada por meio de um processo legislativo específico do seu ordenamento pátrio. Assim, os Estados- membros abdicam de parte da soberania dos Estados para, destarte, alcançar o máximo de efetividade das normas comunitárias a fim de se alcançar os objetivos da União Europeia (BORCHARDT, 2011). Trata-se de um fenômeno jurídico singular e que somente se faz possível pela aplicação dos princípios que passam a ser estudados.

\section{BREVE HISTÓRICO DA UNIÃO EUROPÉIA}

A União Europeia emerge-se no contexto do Pós Segunda Guerra Mundial, em um cenário econômico, social e politico que demandava a união mútua de esforços dos países europeus para a reestruturação dos aspectos basilares de cada Estado (TAVARES, 2006). Tratava-se, assim, não somente de um anseio relacionado aos aspectos gerenciais de cada país, mas sim do estabelecimento de uma unidade harmônica com o fim de minimizar a tentativa de novos conflitos bélicos ou diplomáticos, almejando-se, igualmente, uma integração entre povos e o despertar da identidade europeia no cidadão.

Em um primeiro momento, sob o contexto do Pós Guerra, estabeleceu-se as organizações euro-atlânticas, caracterizadas como uma aliança dos países europeus precipuamente com os Estados Unidos da América, visando o apoio para a reconstrução destes, inicialmente com fulcro no apoio comercial (BORCHARDT, 2011). Surge, dessa forma, em 1948, as Organizações Europeias de Cooperação Econômica (OECE) onde o governo norte- americano, sob a influência da doutrina preconizada pelo Plano Marshall, estabeleceu um plano de recuperação dos países europeus aliados. Posteriormente, emergiu-se no cenário europeu a NATO, em 1949, que almejava atrelar à proposta de recuperação uma 
aliança militar entre os países europeus, os Estados Unidos da América e o Canadá. Em 1954, com o fito de lograr uma maior integração no âmbito da política de segurança, os países europeus assinam o Tratado de Bruxelas, em 1954, estabelecendo a União da Europa Ocidental (BORCHARDT, 2011).

Igualmente, criou-se em outra perspectiva, no ano de 1949, o Conselho da Europa, sendo este idealizado como um organismo para a cooperação internacional entre os países europeus. Ressalta-se, entretanto, que neste momento ainda não há a previsão da criação de uma União autônoma a fim de promover o processo integracional. No mesmo sentido, Em 1994 foi criada a Organização para a Segurança da Europa, para a promoção da confiabilidade entre os países europeus, bem como para o estabelecimento de uma rede de segurança (BORCHARDT, 2011).

Por conseguinte, preponderam como o cerne do processo integracional europeu a celebrações dos seguintes tratados: Tratado de Paris (1951) e do Tratado de Roma (1957) e Tratado de Maastricht (1992) e o Tratado de Lisboa (1997). Tais tratados diferenciam-se das alianças e acordos cooperacionais outrora estabelecidos, mormente pelo fato de que neles os países europeus renunciam parte de sua soberania em prol de uma unidade integrativa (BORCHARDT, 2011). Inicialmente, com o fito de "institucionalizar o seu espaço econômico", ideia concebida com a assinatura do Tratado de Paris, para que os países pudessem exercer um harmonicamente um maior controle e valorização dos seus produtos, sem interesses externos (TAVARES, 2002, p. 18).

Após o Tratado de Paris, sobreveio o Tratado de Roma, que instituiu a Comunidade Econômica Europeia e a Comunidade Europeia da Energia Atômica, em 1957. Com o Tratado de Maastrich, em 1992, percebeu-se o ato constitutivo da União Europeia, não concebida como nos moldes atuais, mas destacando-se como um avanço para se lograr com uma Europa coesa e harmônica. Posteriormente, sobrevieram o Tratado de Amsterdã (1999) e o Tratado de Nice (2003). O Tratado de Amsterdã revelou-se de primordial importância, na perspectiva do Tratado da Constituição Europeia, uma vez que possibilitou a maior cooperação entre os Estados europeus baseados em disposições que regulariam uma inédita e singular União Europeia.

Por fim, em 2007, emerge no cenário europeu o Trata do Lisboa ou Tratado da União Europeia. Trata-se de um tratado com um viés reformador, onde um dos objetivos era o de conferir maior atuação interna, revogando-se os outros tratados constitutivos em prol de um texto uno e que, consequentemente, conferiria maior legitimidade democrática à União 
Europeia, agora fusão da União Europeia e da Comunidade Europeia. ${ }^{1}$ Assim, com o Tratado de Lisboa, a eficácia do Direito da União tornou-se mais sólida e com mecanismos normativamente previstos para a sua aplicabilidade uniforme em toda a União Europeia, com o estabelecimento de uma estrutura autônoma cujas competências são cuidadosamente delimitadas.

\section{OS PRINCÍPIOS NO DIREITO DA UNIÃO EUROPÉIA: CONSIDERAÇÕES GERAIS}

O arcabouço principiológico do Direito da União proporciona uma identidade singular à União Europeia, pelo fato de introduzir em seu Direito diretrizes outrora não verificadas, seja no âmbito do Direito Público, ou seja, no âmbito do Direito internacional (LEAL et al., 2001).

Nessa perspectiva, tratando princípios como mandamentos de otimização, que ordenam a realização de algo na medida do possível, considerando-se as condições fáticas e jurídicas evocadas no caso concreto (ALEXY, 2008), destacam-se no Direito da União, além do princípio da eficácia direta e aplicabilidade direta outros princípios que subsidiam e correlacionam-se entre si.

Assim, o Tratado da União Europeia assenta-se em diversos princípios fundamentais, como o princípio da liberdade, da democracia e do Estado de Direito. Igualmente, constata-se uma série de princípios atinentes ao Direito Comunitário que embasam as relações jurídicas da União e, consequentemente, dos países membros (TAVARES, 2002)

Dentre os diversos princípios inerentes à União Europeia, perceber-se-á uma nítida relação ente os princípios da autonomia da ordem jurídica- comunitária e do princípio do primado com os princípios cernes deste trabalho. Para que se entenda o âmbito de incidência prática do princípio do efeito direto e da aplicabilidade direta faz-se necessário uma breve menção aos princípios que a eles se correlacionam.

O Direito da União caracteriza-se por ser autônomo, ao passo que não se trata de uma ordem jurídica internacional nem se confunde com o direito interno dos países europeus (GORJÃO, 2010). Nesse sentido, Rui Manoel Moura Ramos aduz acerca da peculiaridade de tal autonomia, necessária à configuração do Direito da União:

\footnotetext{
${ }^{1}$ Borchardt destaca que prevalecem no âmbito do direito da União as disposições tratadas no Tratado da UE, bem como os preceitos estabelecidos no Tratado sobre o funcionamento da EU e no Tratado que institui a comunidade europeia de Energia atômica (BORCHARDT, 2011, p. 14).
} 
[...] o que impressiona não é tanto que o Direito Comunitário possa produzir efeitos no seio das ordens estaduais, que prevaleça sobre toda e qualquer regra nacional, independentemente da natureza jurídica desta, e que, no interior dos sistemas nacionais, a sua interpretação esteja sujeita a um controlo, levado a cabo por instâncias comunitárias. Antes, o que é significativo é que tudo isso resulta do próprio Direito Comunitário e não das ordens jurídicas nacionais [...] (RAMOS, 1994, p. 100-101).

Dessa forma, entende-se que para o alcance de êxito na estipulação mútua dos países membros em atribuir à União competências e diretrizes para direcionar as condutas e preceitos integracionais, faz-se necessário a autonomia, e não a subordinação, haja vista que os julgamentos do Tribunal de Justiça da União Europeia, bem como as normas elencadas no Tratado da União Europeia, decorrem do anseio de cada país signatário a constituir uma União, com poderes legiferantes e jurisdicionais, aptos a produzirem efeitos no ambiente comunitário e, consequentemente, no âmbito interno de cada Estado (LEAL et al, 2001). Assim, o Direito da União consubstancia-se como autônomo em relação à ordem jurídica internacional e aos Estados-membros a fim de operacionalizar consoante os anseios dos países responsáveis por sua criação.

No mesmo sentido, desvela-se necessário estabelecer algumas considerações acerca do princípio do primado, por onde se entende que o Direito Comunitário revela-se hierarquicamente superior ao direito interno dos países europeus, no sentido de que a jurisdição nacional deve respeitar as normas de direito comunitário implicando, inclusive, na não aplicação de preceitos normativos contrários às disposições da União, conferindo, assim a primazia de sua aplicação (PIÇARRA, AMARAL, 2008).

Dessa forma, subsistindo o conflito de interesses legalmente tutelados pela legislação nacional de um Estado- Membro e pelo Direito da União, este deverá ser dirimido consoante as regras do direito comunitário, sendo, pois, o Tribunal de Justiça da União Europeia competente para dirimir tal impasse. Sobreleva-se, assim, o primado do Direito da União, como elucida Fernando Horta Tavares:

É importante observar que as disposições nacionais que regem os conflitos entre normas jurídicas não se aplicam às relações com a legislação comunitária, pois esta não é parte integrante da legislação nacional. Em consequência, qualquer conflito entre a legislação comunitária e a legislação nacional deve ser resolvido com base na ordem jurídica comunitária (2002, p. 26).

O princípio da primazia, outrossim, destaca-se pela no sentido de corroborar com a ideia de que as prescrições normativas do Direito Comunitário possuem o condão de tornar inaplicáveis as disposições do Direito nacional, quando contrárias ao estabelecido no Tratado (TAVARES, 2002). 
Consequentemente, sobreleva-se o princípio da subsidiariedade no que tange à disposição de parte das soberanias nacionais para a constituição de uma União dotada de um Direito autônomo a aplicável diretamente aos Estados Membros. Por meio deste princípio, o Tratado de Lisboa aduz que a União somente intervirá quando o objeto da ação não poder ser satisfativamente alcançado pelos países signatários, mas que poderá sê-lo se elevados ao nível da União (GORJÃO, 2010). Trata-se, então, de um reflexo com o federalismo onde se mantêm a integridade e independência dos países europeus (TAVARES, 2002). Quanto às competências, Miguel Gorjão aduz sobre o princípio da subsidiariedade:

\begin{abstract}
Importa acentuar, primeiro, que o princípio só vale nos domínios de competência concorrente entre Estados membros e a União. Com efeito, subordinada a capacidade jurídica da União ao princípio da atribuição, o princípio não poderia valer em domínios totalmente estranhos à atribuição da União. Noutra vertente, o tratado é explicito na afirmação de que o princípio não deve ser aplicado no domínios de atribuição exclusiva da União. (GORJÃO, 2010, p. 384)
\end{abstract}

Por meio das menções aos aludidos princípios, verificar-se-á que os mesmos complementam ou integram um arcabouço de princípios que visam manter a harmonia e integração, de modo efetivo e independente dos Estados Membros da União Europeia, onde os princípios do efeito direto e da aplicabilidade serão oportunamente estudados.

\title{
4 O PRINCÍPIO DO EFEITO DIRETO
}

O princípio do efeito direto pode ser compreendido, igualmente, como principio da efetividade e consubstancia-se como um princípio inovador no âmbito do jurídico². Ele subsidia a invocação das normas do Direito da União, perante a órgão jurisdicionais nacionais, por parte dos particulares, seja em face do Estado ou em face de outros particulares. Este se denomina efeito direto horizontal, enquanto aquele se refere ao efeito direto vertical (GORJÃO, p. 402). Neste âmago, existem as normas de efeito direto material, onde se reconhece direitos e se impõe deveres, bem como os de efeito direto de natureza formal onde tal efeito advém tão somente da expressa previsão em norma da União (GORJÃO, p. 402).

\footnotetext{
${ }^{2}$ Trata-se de um princípio que para Miguel Gorjão encontra-se inserido como uma sub divisão do princípio da efetividade, juntamente com o princípio do primado, o princípio da uniformidade de aplicação, da interpretação conforme e da responsabilidade civil dos estados membros por violação do Direito da União Europeia (GORJÃO, 2010).
} 
O precedente do aludido princípio encontra-se no acórdão Van Gend em Loos, do Tribunal de Justiça da União Europeia, datado de 05 de fevereiro de 1963 (GORJÃO, 2010). Nele, julgou-se uma questão prejudicial levantada pela jurisdição da Holanda, onde a empresa de transporte Van Gend e Loos considerava contrários às prescrições do Direito da União as quantias pecuniárias atinentes aos direitos aduaneiros da Alemanha para os Países Baixos, no que tange às importações. Tal pratica comercial abusiva possibilitou que o Tribunal de Justiça da União Europeia aplicasse o princípio do efeito direto vertical uma vez que permitiu que um particular invocar as normas do direito da União a fim de resolver um impasse nitidamente contrário aos preceitos comunitários europeu ${ }^{3}$.

Dessa forma, o Tribunal de Justiça da União Europeia conclui que o Direito Comunitário configura-se como uma fonte autônoma, em virtude da sua natureza originária específica, onde não pode ser oposto em juízo $m$ um texto interno, qualquer que seja, sem que perca a sua natureza comunitária (...) (GORJÃO, 2010, p. 407).

As diretivas comunitárias são transpostas, geralmente, por meio de mecanismos nacionais para que, por conseguinte, produza efeito direto. Caso não ocorra a transposição de uma diretiva comunitária ou transposição incorreta, por parte dos Estados- membros reconhece-se o fenômeno do efeito direto excepcional, sendo este cessado apenas quando sanado o vício ou omissão quando da transposição de determinada diretiva, aplicável nos casos do efeito direto vertical, uma vez que os particulares não devem arcar com as transposições equivocadas de diretivas (PIÇARRA, 2009).

Ante a inobservância do efeito direto horizontal de uma diretiva, as autoridades e instâncias nacionais obrigam-se a aplicar a regra nacional em conformidade com a diretiva comunitária (PIÇARRA, 2009).

Trata-se, desse modo, de um mecanismo de inafastabilidade dos princípios da autonomia e do primado no âmago do Direito Comunitário. Uma transposição equivocada quanto a real intencionalidade da norma no contexto do Direito da União acarreta na responsabilidade do Estado- Membro, caso a diretiva violada confira direitos aos particulares e apresente o nexo causal entre a violação e o dano. Ressalta-se, assim, que a não transposição de uma diretiva comunitária configura uma violação ao Direito da União (PIÇARRA, 2009).

\footnotetext{
${ }^{3}$ Ressalta-se que o Tribunal de Justiça da União Europeia conferiu o efeito direto à diretrizes normativas do direito originário e direito derivado, bastando a observância de sua precisão e incondicionalidade (GORJÃO, 2010).
} 
Sobreleva-se, dessa forma, o princípio do efeito direto para subsidiar o âmbito de aplicação da norma comunitária na jurisdição nacional dos Estados- Membros, bem como na relativa ao Direito da União, no Tribunal de Justiça. Constata-se que o efeito direto tem como principal resultado o controle jurisdicional das disposições e contextos contrários aos preceitos comunitários onde os particulares tem a possibilidade de invocar a aplicação do Direito comunitário ao caso concreto.

Ressalta-se, nesse ínterim, que nem toda a norma comunitária é dotada de efeito direto. Para que haja tal efeito, faz-se necessário que a norma seja positiva, clara e precisa e que traga uma disposição incondicional sem vinculação a quaisquer pendencias ou condições, precisando ser, portanto, completa (LEAL et al., 2001) ${ }^{4}$.

Neste diapasão, as normas do Direito Comunitário são dotadas de aplicabilidade direta, conquanto, podem não produzir efeitos diretos. Esclareça-se, assim, a aplicabilidade direta não acarreta o efeito direto, haja vista que existem normas diretamente aplicáveis que não criam direitos subjetivos tuteláveis, conforme se analisará a seguir.

Esclareça-se, conquanto, que para se reconhecer o efeito direto de uma norma comunitária deve-se atentar a alguns critérios sem os quais não há de se falar na incidência do instituto. Condições como a positividade da norma, em que se trabalha com uma norma perceptiva e não programática; suficiência da norma, a fim de que contenha em si todos os elementos para sua aplicação concreta; vocação da norma em conferir direitos subjetivos, criando obrigações ou direitos que os tribunais possam salvaguardar e por fim, a condição de incondicionalidade normativa, no sentido de se obter uma norma precisa (CAMPOS, 1997).

No mesmo sentido, o princípio do efeito direto repercute na esfera jurisdicional quando o Direito da União possibilita que o tribunal nacional de cada Estado- Membro não aplique as normas internas dissonantes às normas comunitárias. Os tribunais nacionais funcionam, nessa perspectiva, como tribunais comunitários de direito comum, em uma relação de cooperação entre estes com o Tribunal de Justiça da União Europeia, competente para dirimir conflitos entre a interpretação e uniformização da lei comunitária. Nesse contexto, existe a possibilidade de recurso encaminhado diretamente para o TJ em face de decisões contraditórias aos preceitos comunitários, proferidas pelos tribunais nacionais (PIÇARRA, 2009).

\footnotetext{
${ }^{4}$ Ressalta-se que, no que tange às diretivas comunitárias, inexiste efeito direto na invocação de uma diretiva por particular em face de outro. Este é estritamente vertical (LEAL et al., 2001).
} 
Outro exemplo de cooperação entre os referidos tribunais consiste no instituto do reenvio necessário previsto no art. $234^{\circ}$ do TCE, que permite a apreciação do TJ, em última instância, das decisões atreladas à interpretação e aplicação prática do Direito da União. Ressalta-se que nas hipóteses em que o tribunal do Estado-membro proferir a decisão em última instância, o reenvio será obrigatório (PIÇARRA, 2009).

Destarte, percebe-se que o princípio do efeito direto consubstancia-se como um dos mais importantes princípios basilares do Direito da União, que possibilita que os particulares invoquem as normas comunitárias em sua jurisdição nacional, seja contra o Estado ou contra outro particular, criando-se direitos subjetivos para os mesmos, em o tradicional procedimento de ratificação dos Estados para a recepção das normas elencadas nos tratados constitutivos do Direito da União.

\section{O PRINCÍPIO DA APLICABILIDADE DIRETA}

A aplicabilidade direta consiste, para Miguel Gorjão, em um desdobramento do princípio da efetividade, no qual se observa a uniformidade, prevalência e interpretação conforme o Direito da União (GORJÃO, 2010). Trata-se, pois, do principio subsidiador do ingresso das normas jurídicas comunitárias na esfera jurídica dos Estados- membros da U.E., criando de modo autônomo, direitos atrelados aos com os preceitos comunitários, prescindindo, para tanto, a recepção das aludidas normas pelo direito nacional (LEAL et al., 2001). Assevera-se, conquanto, uma diferença em comparação com o efeito direto ou útil, que se refere à consequência da criação de direitos subjetivos aos particulares com por meio da aplicabilidade direta das normas comunitárias europeias:

\footnotetext{
No estudo da diretiva, sobressai a distinção entre a aplicabilidade direta e efeito direto. A aplicabilidade direta, como já demonstrado, pressupõe a inserção de norma comunitária no direito doméstico, independentemente de qualquer manifestação de recepção. $\mathrm{O}$ efeito direto é a noção construída pela jurisprudência do $\mathrm{TJ}$ e diz respeito à consequência da incorporação do preceito comunitário ao ordenamento jurídico nacional: sua invocação perante a jurisdição nacional. Assim, efeito direto é a qualidade da norma comunitária pelo critério da criação automática de direitos subjetivos tuteláveis em juízo (LEAL et al, 2011, p. 149).
}

No mesmo sentido, João de Mota Campos constata que o efeito direto ou imediato relaciona-se com a atribuição de um direito subjetivo criado pela norma comunitária ao particular, que pode ser invoca-la em juízo, ao passo que a aplicabilidade direta consubstancia-se em um instituto mais amplo, que engloba o efeito direto (1997, p. 247). Para tanto, constata-se que toda norma comunitária que possui um efeito direto decorrente da 
aplicabilidade direta, não sendo o mesmo para uma norma diretamente aplicável, que não necessariamente gerará a atribuição de direitos e imposição de uma obrigação (CAMPOS, 1997).

Demais disso, a norma comunitária europeia, diretamente aplicável pelos tribunais, caracteriza-se pela possibilidade de sua invocação por parte dos particulares, por meio da invocabilidade em juízo das normas que criam ou impõe obrigações entre os mesmos. Os tribunais nacionais, assim, se comprometem a cooperar em prol dos fins almejados pelo Direito da União (CAMPOS, 1997). Percebe-se, então, a opção de cada Estado- membro em restringir sua soberania, criando um direito autônomo e aplicável as suas esferas jurisdicionais (TAVARES, 2002).

Noutro giro, esclareça-se que não é possível a nacionalização de uma norma comunitária, sendo considerado um ato antijurídico por parte do Estado-membro, ao qual também é vedado a aplicação seletiva de tais conteúdos normativos, haja vista a necessária uniformidade interpretativa no âmbito do Direito da União (LEAL et al, 2001).

No Direito da União, a uniformidade da aplicação das normas comunitárias deve ser observada em um mesmo sentido por parte de qualquer dos países signatários da União Europeia. Atrela-se, neste momento, o instituto do reenvio prejudicial anteriormente estudado, a fim de que, por meio de uma colaboração entre órgãos jurisdicionais nacionais e o Tribunal de Justiça alcance uma interpretação uniforme (GORJÃO, 2010).

Nessa perspectiva, destaca-se, outrossim, a prevalência do Direito da União em face do Direito Nacional, que gera a obrigação dos Estados-membros de garantir a plena efetividade das normas comunitárias, mesmo que isso signifique em deixar de aplicar as disposições normativas nacionais em prol daquelas. Consequentemente, correlaciona-se ao dever de interpretação conforme- conhecido também como princípio do efeito indireto- por meio do qual o operador do direito deverá atribuir ao direito nacional uma interpretação conforme as normas comunitárias europeias, precipuamente no que tange ao seu fim, no sentido de harmonizá-lo com as diretrizes comunitárias.

Com efeito, caso um Estado- Membro desrespeite o Direito da União, quando da aplicação e interpretação normativa, os particulares, por meio do efeito direto e da prevalência de sua aplicação, poderão invocar as normas comunitárias em juízo. Entretanto, deve-se atentar aos requisitos das aludidas normas para que se pleiteie o seu efeito direto: 
podem usufruir do efeito directo (por não reconhecerem aos particulares direitos de forma precisa e incondicional). Por outro lado, mesmo providas de efeito directo, o seu reconhecimento judicial pelas jurisdições nacionais não permite uma total reparação dos prejuízos entretanto sofridos pelos particulares (GORJÃO, 2010, p. 423).

Assim, o incumprimento Estatal em face ao Direito da União acarreta, consequentemente, em uma responsabilidade por violação do direito comunitário. Para tanto, o Tribunal de Justiça da União Europeia atrela ao direito à reparação três elementos, quais sejam, a existência de um nexo de causalidade entre a violação da obrigação de transposição e o prejuízo dos particulares envolvidos; conteúdo identificável e a atribuição de direitos aos particulares (GORJÃO, 2010).

Por tudo quanto exposto, sobressai no contexto do Direito da União Europeia uma peculiaridade acerca da aplicabilidade direta das normas comunitárias: a opção dos Estadosmembros em limitar a sua soberania ao constituir uma ordem jurídica autônoma e capaz de interferir na aplicação do direito nacional, a fim de alcançar um Direito harmônico, em prol de uma comunidade europeia unida (SILVA, 2008).

É dizer, então, a União Europeia caracteriza-se por um marco pós- moderno no que tange à crise dos elementos do Estado, haja vista que se percebe no Tratado de Lisboa disposições estruturantes do Direito da União, bem como de seus mecanismos organizacionais, que muito se assemelha a um texto Constitucional, apesar de não sê-lo.

Os tradicionais elementos do Estado passam a ser questionados ao passo que, na União Europeia, existe uma ordem jurídica autônoma e um efetivo processo integracional sem a observância uniforme das clássicas concepções do que se denomina povo, território e soberania. O povo, nesse contexto, se perfaz nos indivíduos inseridos no contexto da soberania da União Europeia e no território europeu, não anulando, entretanto, a nacionalidade ou a soberania nacional atrelada a cada um dos Estados-membros.

A soberania nacional, igualmente, não mais pode ser assimilada em sua concepção clássica, tendo em vista sua inadequação à nova realidade proposta pela União Europeia, através da qual cada país signatário confere parte de sua soberania em prol da sua criação e efetividade uniforme e integracional.

\section{CONSIDERAÇÕES FINAIS}


O Direito da União Europeia consubstancia-se como uma referência no que tange a sua organização estrutural e aos mecanismos que possibilitam a eficácia de sua integração e uniformidade no âmbito jurídico dos Estados- membros. Os princípios norteadores do Direito da União possibilitam um constante aprimoramento da integração e harmonia das prescrições normativas do direito comunitário, junto ao ordenamento nacional de cada país signatário, de modo que se configura como inaplicável uma norma nacional dissonante com a intencionalidade da norma comunitária europeia.

Para tanto, princípios como do primado, da autonomia, da eficácia e aplicabilidade direta destacam-se por sua auto complementariedade e por sua preponderância no direito comunitário europeu, de modo a funcionarem, outrossim, como mecanismos alicerçantes do Direito da União Europeia.

Com efeito, os países signatários conferem parte de sua soberania à União, de modo que a aplicação das normas legais não mais se vincula exclusivamente ao ordenamento jurídico nacional, uma vez que este deve estar em consonância com as disposições e preceitos comunitários. Nesse contexto, emerge-se o princípio do efeito direto, que confere a possibilidade do particular invocar as normas do direito comunitário em suas jurisdições nacionais, seja na para a atribuição de efeito direto vertical ou horizonte. Ademais, com a aplicabilidade direta das normas comunitárias europeias, percebe-se a inserção do preceito jurídico atrelado ao Direito da União no ordenamento nacional dos Estados- membros, sem a necessidade de manifestação acerca de sua recepção.

No mesmo sentido, o Estado- membro compromete-se a interpretar o seu direito nacional em consonância com o Direito da União, estabelecendo, por conseguinte, uma relação cooperacional do tribunal nacional com o Tribunal de Justiça da União Europeia, a fim de obter maior êxito na uniformidade da aplicação das normas comunitárias.

Desse modo, nos casos de omissão ou mesmo transposição equivocada das normas comunitárias pelos Estados-membros, estes podem responder civilmente pelas violações e prejuízos causados aos particulares destinatários das normas.

Destarte, sobressai o Direito da União como um marco entre os ordenamentos jurídicos mundiais por compreender uma estrutura integracional que muito parece com um Estado. Percebe-se, igualmente, que os elementos do Estado, tradicionalmente concebidos pela doutrina constitucionalista, sofrem uma ruptura quando inseridos no contexto da União Europeia, precipuamente no que tange à limitação da soberania dos Estados- membros em prol da criação de uma União com fins integracionais e harmonizadores. 
Nessa perspectiva, outros blocos econômicos poderão se inspirar na aplicação do princípio do efeito direto e aplicabilidade imediata com relação a suas normas jurídicas, de modo a fortalecer a integração dos mesmos. No caso da América Latina, os países integrantes do MERCOSUL se beneficiariam precipuamente em um momento de crise econômicopolítica, que demanda união de esforços em prol do atendimento das demandas do Direito Comunitário.

\section{REFERÊNCIAS BIBLIOGRÁFICAS}

ALEXY, Robert. Teoría de los derechos fundamentales. Trad. Carlos Bernal Pulido. $2^{\mathrm{a}}$ ed. Madrid: Editora CEPC, 2007.

BARACHO, José Alfredo Oliveira. Teoria geral do direito constitucional comum europeu. Revista da Faculdade de Direito Milton Campos, Belo Horizonte, n. 8, p. 89-115, 2001.

BENJAMIN, Walter. A modernidade e os modernos. 2. ed. Rio de Janeiro: Tempo Brasieliro, 2000.

BENJAMIN, Walter. Sobre Arte, Técnica, Linguagem e Política. Lisboa: Relógio D’Água Editores, 1992.

BOBBIO, Norberto. Teoria geral do direito. Tradução de Denise Agostinetti; Revisão da tradução de Silvana Cobucci Leite. 2. ed. São Paulo: Martins Fontes, 2008.

BONAVIDES, Paulo. A constituição aberta. São Paulo: Malheiros, 2004.

BORCHARDT. Klaus-Dieter. O ABC do direito comunitário. 5 ed. Luxamburgo: Serviço de Publicações das comunidades Europeias, 2000.

CAMPOS, João Mota de. Direito Comunitário. II Volume: O ordenamento jurídico comunitário. $5^{\text {a }}$ ed. Lisboa: Fundação Calouste Gulbenkian, 1997.

CANOTILHO, J. J. Gomes. Direito constitucional e teoria da Constituição. 3. ed. Coimbra: Almedina, 1999.

CUNHA, Paulo de P. e RUIZ, Nuno. O Ordenamento Comunitário e o Direito Interno Português. In: Seminários de Estudos sobre Direito Comunitário, Università degli Studi di Camerino (Itália), pp. 341-352, setembro 2005, p. 347-348.

FONTAINE, Pascal. A Europa em 12 lições. Luxemburgo: Serviço das Publicações da União Européia, 2010.

GORJÃO-HENRIQUES. Miguel. Direito da União: história, direito, cidadania, mercado interno e concorrência. $6^{\text {a }}$. Ed. Coimbra: Almedina, 2010. 
LEAL, Rosemiro Pereira; OLIVEIRA, Allan Helber de; FRANÇA, Gustavo Gomes; MIRANDA FILHO, Juventino Gomes. Curso de Direito Econômico- Comunitário. Porto Alegre: Síntese, 2001.

PIÇARRA, Nuno e AMARAL, Diogo Freitas. O Tratado de Lisboa e o Princípio do Primado do Direito da União Européia: uma "evolução na continuidade". Osasco: Revista Mestrado em Direito, ano 9, nº 1, jan/jun 2009.

PIÇARRA, Nuno. A eficácia do Direito Comunitário. Ano 2009. Disponível em $<$ http://www.google.com.br/url?sa=t\&rct=j\&q=\&esrc=s\&source=web\&cd=3\&ved=0CC4QFj AC\&url=http\%3A\%2F\%2Fwww.fd.unl.pt\%2Fdocentes_docs\%2Fma\%2Fnp_MA_3545.doc \&ei=52naU5zhCfXIsASgrYKICw\&usg=AFQjCNE9ilxNtCPYiRv_VkRcp6XnJIJUA\&sig2=I6yg3gcv-Mz2yib9PsqHDg\&bvm=bv.72185853,d.cWc>. Acesso em 23 de junho de 2014.

RAMOS. Rui Manuel Moura. Das comunidades à União Europeia. Coimbra: Editora Coimbra, 1994.

SANTOS, Antonio Carlos; GONÇALVES, Maria Eduarda; y, MARQUES, Maria Manuel Leitão. Direito Económico. Coimbra: Almedina, 1995.

SILVA, José Afonso da. Curso de Direito Constitucional Positivo. 36. ed. São Paulo: Malheiros Editores, 2013.

SILVA, Maria Manuela Magalhães. Soberania e União Europeia. In "Nos 20 anos do Código das Sociedades Comerciais - Homenagem aos Profs. Doutores A. Ferrer Correia, Orlando de Carvalho e Vasco Lobo Xavier". Coimbra: Coimbra Editora, Volume III, Fevereiro de 2008.

TAVARES, Fernando Horta. A ação de incumprimento no processo comunitário e sua exequibilidade no espaço supranacional. 2002. 218 f. Tese (Doutorado)- Pontifícia Universidade Católica de Minas Gerais, Belo Horizonte.

TAVARES, Fernando Horta. O Direito da União Europeia: autonomia e princípios. Ano 5, no 2, 2006.Disponível em:<

http://www.fmd.pucminas.br/Virtuajus/2_2006/Docentes/pdf/Fernandoh.pdf $>$. Acesso em 25 de junho de 2014.

TAVARES, Fernando Horta, SANTOS, Rubens José dos. Direitos. Princípios e garantias fundamentais: fundamentos de legitimidade do Estado Constitucional Democrático de Direito. In: Teoria geral do Direito Público- Institutos jurídicos fundamentais sob a perspectiva do Estado de Direito Democrático. Belo Horizonte: Del Rey, 2013.

VILARIÑO PINTOS, E. La construcción de la Unión Europea, Madrid: Arco, 1996.VIOTTI,

KAUPPI (eds.) International Relations Theory: Realism, Pluralism, Globalism. 2 ed. New York: Macmillan Publishing Company, 1993. 